\title{
PODOBNOST PRIRODNIH STENSKIH MATERIJALA U BOSNI I HERCEGOVINI ZA GRAĐENJE KOLOVOZNIH KONSTRUKCIJA
}

Doc. dr Igor Jokanović, dipl.građ.inž. ${ }^{1}$

Dragana Zeljić, dipl.građ.inž. ${ }^{2}$

Žarko Grujić, dipl.građ.inž. ${ }^{2}$

mr Bojana Grujić, dipl.građ.inž. ${ }^{2}$

UDK: UDK 625.863(497.6)

DOI: 10.14415/zbornikGFS28.09

Rezime: Danas, prateći maksimalnu evoluciju transporta drumskim saobraćajnicama, postoji velika potreba za korišćenjem samo najkvalitetnijih materijala za izgradnju savremenih puteva. Svi ti materijali se nalaze oko nas, ali ih je potrebno na pravi način iskoristiti, što pretpostavlja i poznavanje njihovih svojstava i predviđanje ponašanja $u$ gotovim konstrukcijama. U Bosni i Hercegovini postoji dovoljno kapaciteta za dobijanje kamenih agregata radi proizvodnje svih slojeva kolovoznih konstrukcija. U radu se prikazuje procedura i definišu osnovna ispitivanja stenskih materijala kako bi se dokazala njihova upotrebljivost za izgradnju kolovoznih konstrukcija u Bosni i Hercegovini. Daje se kratak osvrt na osnovne geološke karakteristike ovog prostora, te navode i opisuju kamenolomi najvećeg kapaciteta. Glavni cilj rada je da se utvrdi da li su materijali koji se mogu eksploatisati na prostoru Bosne i Hercegovine dovoljno kvalitetni da bi se koristili za građenje kolovoznih konstrukcija, kao i gde i na koji način se isti mogu upotrebiti.

Ključne reči: kolovozne konstrukcije, stenski materijali, građenje, kvalitet, podobnost

\section{UVOD}

U postojećim uslovima kada saobraćajno opterećenje praktično konstantno raste, a konfiguracije vozila za transport ljudi i roba se neprestano usavršavaju kako bi se ostvario što veći prevozni kapacitet i transportni rad, neophodno je da se za izgradnju savremenih puteva koriste samo najkvalitetniji materijali. Svi ti materijali se u suštini nalaze u našem okruženju, samo ih je potrebno iskoristiti na pravi način. S tim u vezi je i potreba poznavanja njihovih svojstava, kao i predviđanje ponašanja tih materijala u gotovim konstrukcijama.

U Bosni i Hercegovini ( $\mathrm{BiH})$ su tek pre desetak godina počele aktivnosti izgradnje puteva najvišeg ranga, međutim prethodno nisu obavljene detaljnije analize raspoloživih

\footnotetext{
1 Univerzitet u Novom Sadu, Građevinski fakultet Subotica, Kozaračka 2a, Subotica, Republika Srbija, e-mail: jokanovici@gf.uns.ac.rs

2 Univerzitet u Banjoj Luci, Arhitektonsko-građevinsko-geodetski fakultet, Bulevar vojvode Stepe Stepanovića 77/3, Banja Luka, Republika Srpska, Bosna i Hercegovina, dzeljic@agfbl.org, zgrujic@agfbl.org, bgrujic@agfbl.org
} 
kapaciteta. Ovo se naročito odnosi na raspoloživost stenskih materijala za kolovozne konstrukcije koji moraju ispunjavati sve strožije uslove. BiH poseduje značajan sirovinski kapacitet koji treba iskoristiti na pravi način i nema razloga da se korišćenjem istih ne izgradi kvalitetna putna mreža koja bi pružala odgovarajući nivo usluge i ekvivalentne prihode.

\section{GEOLOŠKA GRAĐA BOSNE I HERCEGOVINE}

Geološka građa teritorije BiH (Slika 1) je rezultat duge geološke prošlosti i u velikom obimu predodređuje karakteristike stenskih masa koje se koriste u građevinarstvu.



Slika 1. Geološka građa prostora Bosne i Hercegovine [1]

U prostoru nekadašnje Tetis geosinklinale se nalazila i teritorija BiH. Tetis geosinklinala je ležala između afričke ploče na jugu i evro-sibirske ploče na severu. Na teritoriji BiH su se taložile stene i sedimenti počevši od arhajske ere pa do kraja tercijara. Najstarije naslage u prostoru $\mathrm{BiH}$ potiču iz starijeg paleozoika odnosno iz silurske ere. Naslage silurske starosti su zastupljene u prostoru bosanskog škriljavog gorja u grupi planina Vranica-Zec 
planina-Bitovnja. Ove mase su predstavljene škriljavim naslagama, mermerima, dolomitima, krečnjacima i klasičnim stenama, koje su impregnirane raznovrsnim magmatskim stenama. Naslage su dodatno i tektonski jako polomljene, izrasedane i ubrane. Na silurskim naslagama u istom okeanskom basenu su se taložile i naslage starijeg i mlađeg paleozoika, odnosno naslage devona, karbona i perma. Naslage paleozoika su predstavljene pretežno klasičnim, a manje karbonatnim strukturama koje su u pojedinim mestima izmetamorfozirane. Naslaga paleozoika uglavnom ima u unsko-sanskom području, srednjebosanskim škriljavim planinama, istočnoj i jugoistočnoj Bosni, te Prosari i Motajici.

Srednjebosanski paleozojski kompleks se proteže od Ivan Sedla na jugoistoku do Jajca na severozapadu, te između sarajevsko-zeničkog basena na severoistoku i gornjevrbaskog uskopljanskog basena na jugozapadu. Paleozoik na prostoru jugoistočne Bosne je tzv. pračanski paleozoik. Proteže se istočno i severoistočno od Jahorine do Drine. U pračanskom paleozoiku su uglavnom zastupljene krečnjačke stene iz devona. Pored devonskih naslaga tu su i naslage iz karbona. Severoistočno od pračanskog paleozoika je drinski paleozoik koji se pruža od Srebrenice do Zvornika u slivu Jadra i u donjem toku Drinjače. Paleozojske naslage su razvijene u okolini ključa i Sanskog Mosta. Ovo područje se naziva unsko-sanski paleozoik. U unsko-sanskom paleozoiku, u mestima Bosanski Novi i Ljubija, su zastupljene naslage iz devona. Karbon čine različiti klastiti u kojima ima i magmatskih stena, a nešto dolomita i krečnjaka.

Sledeća era u razvoju zemljine kore na prostoru BiH je mezozojsko tektonski orogeni ciklus, koji se razvio u tri podere: trijas, jura i kreda. Mezozojske naslage su široko rasprostranjene u unutrašnjim, središnjim i vanjskim Dinaridima. Mezozojske naslage $u$ vanjskim Dinaridima su predstavljene klasičnim karbonatnim naslagama, dok središnji i unutrašnji Dinaridi imaju vulkansko-sedimentne i flišne naslage. Trijas je rasprostranjen u pojasu od Vrnograča i Bosanskog Novog preko zapadne Bosne, severne i severoistočne Hercegovine i jugoistočne Bosne.

Drugi, širi pojas se proteže od Vareša preko Olova, Glasinca i Romanije do Višegrada. Naslage jure zauzimaju najveći deo u vanjskom Dinarskom pojasu, gde je uglavnom razvijen u krečnjačko-dolomitnom facijesu. Nalazi se na prostoru od Bihaća do Gacka i Trebinja. Jurske starosti je i vulkanogena sedimentna formacija u centralnoj ofiolitskoj zoni od Kozare preko srednje Bosne do Drine. Kreda je rasprostranjena u širim ili užim pojasevima od granice s Crnom Gorom pa sve do Bosanskog Grahova, Bihaća i Bosanske Krupe na severozapadu, zatim u unutrašnjosti između Jajca, Banje Luke te planina Ranče i Vlašića. Početak taloženja ove epohe je nastupio pre 70 miliona godina i traje sve do danas. Kvartar je prisutan u geološkoj građi Dinarida na području BiH.

Najmlađa era u razvoju zemljine kore je kenozoik koji je prisutan i na prostoru BiH. Deli se na dve velike epohe: tercijar i kvartar, dok se kvartar deli na paleogen i neogen. Naslage paleogena su razvijene na ivičnim severoistočnim i severnim delovima, te na južnim i jugozapadnim delovima $\mathrm{BiH}$. U ovim naslagama su zastupljene magmatske stene sa orunjenjima, te posebno ugljonosne naslage.

U neogenu su, pored krečnjačkih i klasičnih naslaga, prisutne i slatkovodne naslage, od kojih je najveći sarajevsko-zenički ugljonosni basen. Najmlađe pliocenske i kvartarne naslage su široko rasprostranjene, pogotovo u kotlinama i dolinama. Posebno se izdvajaju holocenske naslage predstavljene šljuncima, peskovima, ilovačama i glinama, te sedrenim i pećinskim naslagama. 


\section{ISPITIVANJA OSNOVNIH SVOJSTAVA STENSKIH MASA}

Danas se ne može zamisliti ni jedan proizvod priznat na tržištu, a da nije nastao kroz niz laboratorijskih ispitivanja, niti se njegova proizvodnja može zamisliti bez neprestanog laboratorijskog praćenja. Laboratorijska ispitivanja su u većini država regulisana standardima, a standard je odraz potreba i mogućnosti jedne zemlje u njenim naporima za postizanje kvaliteta u bilo kojoj delatnosti.

Mineralni materijali koji se koriste u kolovoznoj konstrukciji i podležu atestiranju su: kamen (kao sirovina), frakcionisani kameni agregat, prirodni i drobljeni pesak i kameno brašno [2]. Bitno je naglasiti da svaki proizvođač stenskog materijala, odnosno svaki kamenolom, mora proveriti kvalitet raspoloživog materijala i dobiti atest za svoj proizvod. Institucije nadležne za atestiranje materijala koji se koriste za građenje puteva u BiH izdaju atest prema Naredbi o obaveznom atestiranju frakcionog kamenog agregata za beton i asfalt (Službeni list SFRJ, br. 41/87) [3].

Tek nakon atestiranja proizvođač može, uz prilaganje atesta, kupcu prodati materijal. Nije suvišno napomenuti da kupac ima pravo i nakon toga što kupi proizvod, ako nije zadovoljan, da zatraži od neke druge nadležne institucije da atestira proizvod koji je kupio. $\mathrm{Na}$ taj način se zatvara krug koji čine proizvođač, kupac i atestna institucija, čija je uloga ključna u ovom procesu.

$\mathrm{Na}$ žalost, u ovom procesu se događaju i veliki propusti tako da se često može svedočiti neadekvatno/nekvalitetno izvedenim radovima zahvaljujući tome što je korišćen materijal slabijeg kvaliteta od zahtevanog. To se uglavnom dešava kao posledica neredovnog atestiranje proizvoda od strane proizvođača (kamenolom) ili izostankom istog. Naredbom [3] je predviđeno da se kontrola kvaliteta koju obavlja nadležna institucija vrši svakih pola godine, što u određenim situacijama nije odgovarajuće. Ponekad su stenske mase toliko ujednačene tako da velike količine materijala poseduju ista svojstva pa bi pomenuti atest mogao da se izdaje i na primer svakih godinu dana. Međutim češći je slučaj da je sastav sirovine (stene) toliko raznolik i ima toliko proslojaka materijala koji nije dovoljno kvalitetan da je neispravno izdavati atest svakih pola godine, već bi to trebalo raditi znatno češće. Takođe je potrebno da svaki proizvođač poseduje vlastitu laboratoriju u kojoj se svakodnevno ispituje dobijeni proizvod, a da se laboratorijski rezultati dostave nadležnoj instituciji koja donosi konačnu odluku o podobnosti materijala dobijenog u kamenolomu. Značaj minerala u inženjerskoj geologiji je vezan za njihovo prisustvo u stenskim masama, koje nazivamo petrogenim mineralima [4]. Ima ih mnogo manje u odnosu na ukupan broj minerala, svega nekoliko desetina. Učestvuju u građi stenske mase i oblikuju je prema svojim karakteristikama. U stenama se pojavljuje i manji broj minerala koji nisu petrogeni. Prisustvo takvih štetnih minerala pogoršava karakteristike stenske mase, posebno kod upotrebe stena u građevinarstvu. Minerali kao fizička tela imaju određene karakteristike po kojima su prepoznatljivi i različiti jedni od drugih. Na njih utiču pre svega hemijski sastav i struktura. Najznačajnije karakteristike minerala koje utiču na kvalitet kolovozne konstrukcije su čvrstoća, tvrdoća i cepljivost.

Stene su u zavisnosti od postanka razvrstane u tri grupe: magmatske, sedimentne i metamorfne stene [4]. Stenske mase karakterišu određena svojstva, od kojih su neka karakteristična za sve grupe stena, a neka za pojedine stene. U cilju detaljnijeg sagledavanja karakteristika stena, neophodno je proučiti njihova svojstva i promene svojstava pod uticajem određenih prirodnih i veštačkih faktora. Određivanje karakteristika

94 | JOURNAL OF FACULTY OF CIVIL ENGINEERING 28 (2015) | 
tla i stena se vrši metodama koje se međusobno dopunjuju, definišući tako njihova određena svojstva.

Obaveznom ispitivanju podležu sledeće karakteristike agregata [3]:

- mineraloško-petrografski sastav;

- sastojci koji sprečavaju hidrataciju cementa;

- pritisna čvrstoća kamena, ako se agregat dobija drobljenjem kamena;

- postojanost agregata ili kamena na delovanje mraza;

- $\quad$ sadržaj ukupnog sumpora i hlorida;

- zapreminska masa zrna;

- upijanje vode;

- $\quad$ sadržaj organskih materija;

- oblik zrna;

- $\quad$ sadržaj grudvi gline;

- $\quad$ sadržaj trošnih/slabih zrna;

- $\quad$ sadržaj lakih čestica;

- obavijenost površine zrna;

- otpornost protiv drobljenja i habanja;

- zapreminska masa u rastresitom i zbijenom stanju;

- ostatak na laboratorijskom situ koje odgovara gornjoj nazivnoj veličini frakcije i prolaz kroz laboratorijsko sito koje odgovara donjoj nazivnoj veličini frakcije (krupni agregat);

- $\quad$ sadržaj sitnih čestica;

- granulometrijski sastav sitnog agregata i modul zrnavosti sitnog agregata.

Fizičko-mehanička svojstva stena koja su bitna sa aspekta izgradnje kolovoznih konstrukcija su:

- $\quad$ pritisna čvrstoća u suvom i vodom zasićenom stanju (BAS ${ }^{3}$ B.B8.012);

- otpornost prema habanju brušenjem (BAS B.B8.015);

- $\quad$ upijanje vode (BAS B.B8.010);

- zapreminska masa sa porama i šupljinama, zapreminska masa bez pora i šupljina i koeficijent zapreminske mase i poroznosti (BAS B.B8.032);

- postojanost upotrebom $\mathrm{Na}_{2} \mathrm{SO}_{4}$ (BAS B.B8.002).

Tehnička svojstva stena koja su bitna sa aspekta izgradnje kolovoznih konstrukcija su:

- obradljivost;

- bušenje stena;

- otpor prema miniranju;

- rastresitost;

- $\quad$ sleganje;

- $\quad$ ponašanje stena na mrazu, povišenoj temperaturi i u prisustvu vode.

\footnotetext{
3 Bosansko-hercegovački standard (BAS) odgovara jugoslovenskom standardu (JUS) pošto je uredbom obavljeno preuzimanje standarda koji su važili u SFRJ.
} 


\section{AGREGAT U KOLOVOZNOJ KONSTRUKCIJI}

Agregat se u kolovoznoj konstukciji upotrebljava u svim slojevima, i to kao nevezan ili vezan (bitumenom ili cementom). Frakcionisani kameni agregat podleže obaveznom atestiranju na osnovu pomenute naredbe [3]. Ovom naredbom su regulisana svojstva koja se ispituju, standardi po kojima se ispituju, obim ispitivanja i način izdavanja atesta.

Ocena kvaliteta se daje prema važećim tehničkim propisima, i to:

- BAS B.B2.010 (Separisani agregat-granulat za beton. Tehnički uslovi);

- BAS B.B3.045 (Kameno brašno za ugljovodonične mešavine. Tehnički uslovi);

- BAS B.B3.100 (Kameni agregat. Frakcionisani kameni agregat za beton i asfalt. Osnovni uslovi kvaliteta);

- BAS U.E4.014 (Projektovanje i građenje puteva. Izrada asfaltnih betona. Tehnički uslovi);

- BAS U.E9.020 (Klasične i savremene podloge za puteve. Tehnički uslovi za izradu);

- BAS U.E9.021 (Asfaltni putevi. Tehnički uslovi za izradu gornjih nosivih slojeva od bitumeniziranog materijala po vrućem postupku);

- BAS U.E9.024 (Noseći slojevi kolovoznih konstrukcija puteva od materijala stabilizovanih cementom i sličnim hidrauličkim vezivom);

- BAS U.E9.028 (Projektovanje i građenje puteva. Izrada donjih nosećih slojeva od bitumeniziranog materijala po vrućem postupku. Tehnički uslovi).

Početna ispitivanja se obavljaju na sirovini (kamen) od koje se dobija proizvod (frakcije kamenog agregata). Kamen mora posedovati određena svojstva da bi se uopšte mogao prerađivati i koristiti za određene slojeve kolovozne konstrukcije. Svojstva kamena za proizvodnju frakcija drobljenog kamenog agregata za asfaltne betone moraju zadovoljiti određene kriterijume, propisane standardom.

\section{KAMENOLOMI U BOSNI I HERCEGOVINI}

U BiH postoji veliki broj većih kamenoloma koji zadovoljavaju potrebe građenja puteva na ovim prostorima, a zbog nedostatka sredstava (prvenstveno finansijskih) se ne istražuju novi potencijalno kvalitetni kamenolomi. Veliki je problem i to što se dobra pozajmišta stenskih materijala uglavnom nalaze na mestima koja nisu dobro infrastrukturno povezana, pa je na taj način otežana njihova eksploatacija.

U krajnjem slučaju slaba povezanost putevima je opšti problem u $\mathrm{BiH}$, pa se otvaraju kamenolomi na pogodnim lokacijama po svaku cenu, iako se zna da će takva sirovina biti manje kvalitetna. Koriste se mašine i alati čiji je radni vek davno iscrpljen, mašine koje su davno izašle iz upotrebe u razvijenim zemljama sveta. Posledica navedenog je da se, uz sav uloženi trud, obično ne mogu postići veći kapaciteti kakvi se postižu u drugim državama u regionu. U ovom radu je obrađeno ukupno 15 kamenoloma iz BiH (Slika 2), koji se pretežno nalaze u Republici Srpskoj zbog dostupnosti podataka, tačnije 13 kamenoloma iz Republike Srpske i 2 kamenoloma iz Federacije BiH.

Od analiziranih 15 kamenoloma, 11 proizvodi frakcije od stenske mase koja je sedimentnog porekla (karbonatnog sastava), dok su u 4 kamenoloma stenske mase magmatskog porekla (silikatnog sastava). 
Što se tiče stena karbonatnog sastava u pitanju su krečnjaci i dolomiti, kao i varijacije krečnjaka i dolomita (krečnjački dolomit i dr). Krečnjak se eksploatiše u sledećim kamenolomima: Derviš Kula, Orlovača, Ljubačevo, Čelar, Grab, Planina, Jasenov Do i Jošanica. Kamenolomi sa dolomitom su: Blatna, Crnolići i Čirakovac. Od stena silikatnog sastava jedino je zastupljen dijabaz koji se eksploatiše u kamenolomima: Trnava, Maglajci, Breštanica i Drugovići.

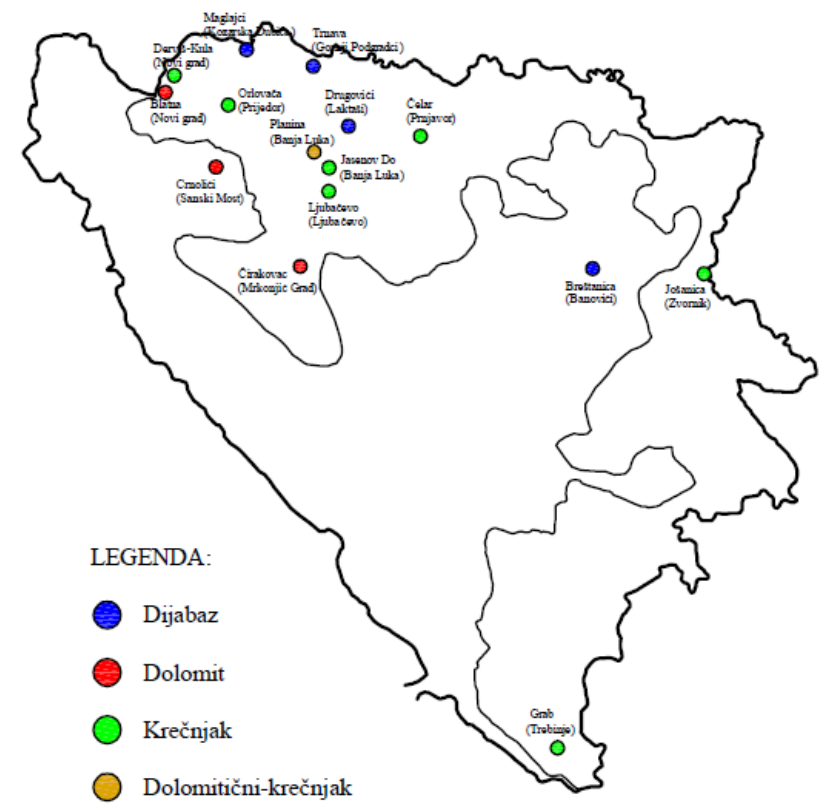

Slika 2. Prikaz analiziranih kamenoloma u Bosni i Hercegovini

\section{PODOBNOST STENSKIH MATERIJALA ZA POJEDINE SLOJEVE KOLOVOZNE KONSTRUKCIJE}

Stenski proizvod, odnosno frakcije različitih veličina poseduju određeni kvalitet koji je potrebno utvrditi i na osnovu čega se ocenjuje podobnost tog materijala za izradu kolovoznih konstrukcija. Kao što je navedeno, zahtevi koji su potrebni da bi se materijal klasifikovao su definisani odgovarajućim standardima, a ocena kvaliteta se daje na osnovu ispitivanja koja vrši nadležna institucija.

Što se tiče kolovozne konstrukcije, poznato je da su uslovi kvaliteta blaži za donje slojeve, a za svaki naredni sloj su sve oštriji tako da se u habajuće slojeve mogu ugraditi samo najkvalitetniji materijali određenog porekla i sastava.

Podobnost materijala za određeni sloj je ocenjivana na osnovu dostupnih atesta koje izdaju nadležne institucije i u kojima su predstavljene karakteristike materijala.

Ocena podobnosti se može sažeto sagledati u Tabeli 1. gde oznaka (+) ukazuje da se pojedini materijali mogu koristiti za određeni sloj, a oznaka (-) da se njihovom upotrebom ne bi postigao zahtevani kvalitet kolovozne konstrukcije, odnosno pojedinačnih slojeva. 
Tabela 1. Podobnost materijala iz analiziranih kamenoloma u Bosni i Hercegovini za građenje kolovoznih konstrukcija

\begin{tabular}{|c|c|c|c|c|c|c|c|c|}
\hline \multicolumn{2}{|c|}{ slojevi kolovozne konstrukcije } & \multicolumn{5}{|c|}{$\begin{array}{c}\text { habajući slojevi } \\
\text { (u zavisnosti od saobraćajnog } \\
\text { opterećenja) }\end{array}$} & \multirow{2}{*}{ 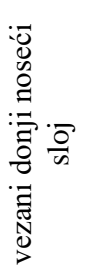 } & \multirow{2}{*}{ 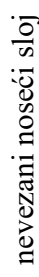 } \\
\hline kamenolom & stena & 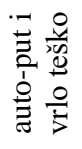 & $\frac{9}{\frac{y}{x}}$ & $\begin{array}{l}\stackrel{\circlearrowright}{\Xi} \\
\stackrel{\mathscr{D}}{\mathscr{D}}\end{array}$ & 韋 & $\begin{array}{l}\frac{0}{3} \\
\frac{0}{3} \\
\frac{0}{5}\end{array}$ & & \\
\hline $\begin{array}{c}\text { Maglajci, } \\
\text { Kozarska Dubica }\end{array}$ & dijabaz & + & + & + & + & + & + & + \\
\hline $\begin{array}{c}\text { Planina, } \\
\text { Banja Luka }\end{array}$ & $\begin{array}{l}\text { dolomitični } \\
\text { krečnjak }\end{array}$ & - & - & - & + & + & + & + \\
\hline $\begin{array}{c}\text { Jasenov Do, } \\
\text { Banja Luka }\end{array}$ & krečnjak & - & - & - & - & + & + & + \\
\hline $\begin{array}{l}\text { Jošanica, } \\
\text { Zvornik }\end{array}$ & krečnjak & - & - & - & + & + & + & + \\
\hline $\begin{array}{c}\text { Breštanica, } \\
\text { Banovići }\end{array}$ & dijabaz & + & + & + & + & + & + & + \\
\hline $\begin{array}{l}\text { Drugovići, } \\
\text { Laktaši }\end{array}$ & dijabaz & - & + & + & + & + & + & + \\
\hline $\begin{array}{c}\text { Crnolići, } \\
\text { Sanski Most }\end{array}$ & dolomit & - & - & + & + & + & + & + \\
\hline $\begin{array}{c}\text { Blatna, } \\
\text { Novi Grad }\end{array}$ & dolomit & - & - & + & + & + & + & + \\
\hline $\begin{array}{l}\text { Derviš Kula, } \\
\text { Novi Grad }\end{array}$ & krečnjak & - & - & + & + & + & + & + \\
\hline $\begin{array}{c}\text { Orlovača, } \\
\text { Prijedor }\end{array}$ & krečnjak & - & - & + & + & + & + & + \\
\hline $\begin{array}{c}\text { Trnava, } \\
\text { Gornji Podgradci }\end{array}$ & dijabaz & + & + & + & + & + & + & + \\
\hline $\begin{array}{l}\text { Ljubačevo, } \\
\text { Ljubačevo }\end{array}$ & krečnjak & - & - & - & + & + & + & + \\
\hline $\begin{array}{c}\text { Čelar, } \\
\text { Prnjavor }\end{array}$ & $\begin{array}{c}\text { krečnjak- } \\
\text { biotransparit }\end{array}$ & - & - & - & + & + & + & + \\
\hline $\begin{array}{c}\text { Čirakovac, } \\
\text { Mrkonjić Grad }\end{array}$ & dolomit & - & - & - & + & + & + & + \\
\hline $\begin{array}{l}\text { Grab, } \\
\text { Trebinje }\end{array}$ & krečnjak & - & - & + & + & + & + & + \\
\hline
\end{tabular}

$\mathrm{Na}$ osnovu karakteristika materijala i zahtevanih parametara ${ }^{4}$ je utvrđeno da se materijali iz svih 15 navedenih kamenoloma mogu ugrađivati u nevezani noseći sloj, uz odgovarajući granulometrijski sastav, a takođe se mogu koristiti i za vezani donji noseći sloj. Kod

\footnotetext{
4 Zbog ograničenog obima rada nisu detaljno prikazane karakteristika materijala iz pojedinačnih kamenoloma i upoređenje istih sa zahtevanim vrednostima parametara. Zainteresovani se mogu obratiti autorima.
} 
habajućeg sloja postoji podela na pet grupa saobraćajnog opterećenja (auto-put i vrlo teško, teško, srednje, lako i vrlo lako saobraćajno opterećenje) tako da materijali iz pojedinih kamenoloma mogu biti korišćeni za habajuće slojeve određenog saobraćajnog opterećenja. Materijali iz svih 15 kamenoloma mogu biti korišćeni za vrlo lako saobraćajno opterećenje, a samo jedan od njih ne ispunjava uslove za lako saobraćajno opterećenje (kamenolom Jasenov Do). Za srednje saobraćajno opterećenje se može koristiti materijal iz 9 kamenoloma (Maglajci, Breštanica, Drugovići, Crnolići, Blatna, Derviš Kula, Orlovača, Trnava i Grab), za teško saobraćajno opterećenje iz 4, a za autoput i vrlo teško saobraćajno samo materijali iz 3 kamenoloma.

Za prve dve grupe saobraćajnog opterećenja (auto-put i vrlo teško, teško opterećenje) uslov ispunjavaju samo kamenolomi dijabaza, što znači stene silikatnog sastava, a stene karbonatnog sastava se ne mogu koristiti za te grupe saobraćajnog opterećenja čak i kada bi teoretski ispunjavali uslove fizičko-mehaničkih karakteristika. Znači za prve dve grupe saobraćajnog opterećenja se mogu koristiti materijali iz kamenoloma: Trnava, Maglajci, Breštanica i Drugovići, od čega se prva tri mogu upotrebiti i za prvu grupu saobraćajnog opterećenja, dok materijal iz Drugovića ne može biti ugrađen u habajuće slojeve auto-puta i vrlo teškog saobraćajnog opterećenja.

Analiza je pokazala da najbolje fizičko-mehaničke karakteristike od svih ispitanih materijala ima stenski materijal iz kamenoloma Trnava u Gornjim Podgradcima. U pitanju je dijabaz sivozelenkaste do tamnosive boje, porfirske strukture i masivne teksture, koji je dovoljno kvalitetan za sve slojeve kolovozne konstrukcije i sve grupe saobraćajnih opterećenja. Ovaj materijal takođe zadovoljava i nešto strožije kriterijume predviđene evropskim normama tako da treba obaviti dalje istražne radove i stvoriti uslove za otvaranje još ovakvih kamenoloma koji će sigurno, u godinama koje slede, pomoći da se izgradi kvalitetna mreža auto-puteva u $\mathrm{BiH}$.

\section{ZAKLJUČAK}

Uzorak koji je analiziran predstavlja oko $75 \%$ proizvodnje kamenih agregata u zapadnom delu Republike Srpske, a rezultati iz ostalih kamenoloma samo dopunjuju sliku stanja. Imajući u vidu geološku građu $\mathrm{BiH}$ i na ostatku prostora bi se najverovatnije odrazio isti trend. Varijetet rezultata pokazuje da postoji dovoljna baza za kvalitetnu izradu svih slojeva kolovozne konstrukcije.

U Republici Srpskoj postoje dovoljni kapaciteti za proizvodnju kvalitetnih kamenih agregata za izgradnju svih slojeva kolovoznih konstrukcija, međutim prostorna raspodela kvalitetnih materijala upućuje na činjenicu da će vremenom troškovi izrade gornjih slojeva na putevima za teško i vrlo teško saobraćajno opterećenje u severnoistočnom i južnom delu rasti zbog povećanja transportnih dužina.

Posebno se ističe materijal iz kamenoloma Trnava kod Gornjih Podgradaca, istovremeno zadovoljavajući i uslove kvaliteta po evropskim normama, te se preporučuje šire istraživanje područja i eventualno otvaranje još ovakvih kamenoloma kroz jednu širu akciju vođenu od strane nadležnih institucija i ministarstva. Naravno, u postojećim ekonomskim uslovima se ne može očekivati da ove institucije i ministarstvo poseduju dovoljno finansijskih sredstava za istraživanja i pokretanje proizvodnje, ali se jednim pravilnim pristupom u obliku javno-privatnog partnerstva i/ili kroz koncesione ugovore može ostvariti privlačenje privatnog kapitala. 


\title{
LITERATURA
}

[1] Geologija Bosne i Hercegovine, http://www.visitmycountry.net/bosnia_herzegovina/bh/index.php/geografija/27vmc/geografija/225-geologija-bosne-i-hercegovine, preuzeto 17.11.2015.

[2] Subotić, P., Priručnik za asfalt, Institut za puteve, Beograd, 1997.

[3] Naredba o obaveznom atestiranju frakcionog kamenog agregata za beton i asfalt, Službeni list SFRJ, br. 41, 1987.

[4] Đurić, N.: Osnove geologije i inženjerske geologije, Građevinski fakultet Subotica, Subotica, 2009.

\section{SUITABILITY OF NATURAL ROCK MATERIALS IN BOSNIA AND HERZEGOVINA FOR PAVEMENT CONSTRUCTION}

\begin{abstract}
Summary: Today, following the maximum evolution of road transport, there is a great need for using only the highest quality materials for the construction of modern roads. All these materials lay around us, but they need to be properly utilized, which assumes the knowledge of their properties and predicting behavior in completed structures. There is enough capacity to obtain stone aggregates for the production of all pavement layers in Bosnia and Herzegovina. This paper outlines procedure and defines the basic tests of rock materials in order to demonstrate their usefulness for the construction of pavements in Bosnia and Herzegovina. It gives a brief overview of the main geological features of the area, and state and describe the quarries with the biggest capacity. The main objective of this paper is to determine whether the materials, owned by Bosnia and Herzegovina, have sufficient quality to be used for the construction of pavements, as well as where and how they can be used.
\end{abstract}

Keywords: pavement structure, rock materials, construction, quality, suitability 